\title{
MEMÓRIA DE VELHAS PROFESSORAS: A NATUREZA E A RELAÇÃO SOCIEDADE-NATUREZA
}

\author{
Memories of old teachers: \\ nature and the nature/society relationship
}

Marilu Mercadante $^{1}$. Rosa Maria Feiteiro Cavalari ${ }^{2}$

Resumo: Este artigo tem como objetivo identificar, a partir da memória de velhas professoras, as concepções de natureza e de relação sociedade-natureza presentes nos depoimentos de professoras que atuaram na rede pública estadual de uma cidade do interior do estado de São Paulo, nas décadas de 1960 e 1970. Constatou-se, por meio das leituras das narrativas, que as professoras apresentam a natureza por meio de diferentes concepções. No que diz respeito à relação sociedade-natureza, evidencia-se a relação conflituosa que se estabelece entre o homem e a natureza. No geral, o homem foi apresentado como aquele que destrói a natureza, caracterizado pelas professoras como ruim e ignorante. Tentar compreender como a natureza e a relação sociedade-natureza se fazem presentes na memória dessas professoras pode contribuir para a construção de novas formas de relação sociedadenatureza nos dias atuais.

Palavras-chave: Natureza. Sociedade. Memórias. Idoso. Educação ambiental.

\begin{abstract}
This research has the objective to identify from the remembrances of old teachers the relation between their conceptions of the natural world and the nature of society. The old teachers are from the state public schools from a city in the county of São Paulo in 60's and 70's. It was found from reading the narratives, that the teachers describe nature with different conceptions. Looking at the nature/ society relationship, it is noticeable that a conflicted relation is established between the man and nature. It can be affirmed, in general, that man was presented as the one who destroys nature, being characterized by the teachers as bad and ignorant. Trying to understand how nature and its relationship to society are present in the remembrances of these masters can help us currently to build new ways of relating nature and society.
\end{abstract}

Keywords: Nature. Society. Memories. Elderly. Environmental education.

\footnotetext{
${ }^{1}$ Instituto de Biociências, Universidade Estadual Paulista “Júlio de Mesquita Filho” (Unesp), Rio Claro, SP. lu.mercadante@yahoo.com.br

${ }^{2}$ Departamento de Educação, Instituto de Biociências, Universidade Estadual Paulista "Júlio de Mesquita Filho" (Unesp). Rio Claro, SP, Brasil.
} 
Mercadante, M.; Cavalari, R. M. F.

\section{Introdução}

Nas últimas décadas, as preocupações com a preservação do meio ambiente e a melhoria da qualidade de vida tornaram-se constantes no nosso dia a dia. O surgimento de uma série de questões relacionadas às várias formas de degradação do meio ambiente vem despertando e motivando grandes parcelas da população a um estado de atenção, no que diz respeito à problemática ambiental.

É importante observar que, no final da década de 1960, o tema natureza/meio ambiente já era um dos pontos centrais nas discussões dos mais diferentes setores da sociedade em vários países. Segundo Gonçalves (1990, p. 12), na década de 1960 ocorreu o crescimento de movimentos que criticavam "não apenas o modo de produção, mas, fundamentalmente, o modo de vida" que se tinha na época.

Ainda de acordo com esse autor, no Brasil, essas movimentações já eram percebidas, e as primeiras lutas ecológicas datam de 1970, no contexto da ditadura militar: "vivia-se sob uma ditadura que se abateu de maneira cruel sobre diversos movimentos como o sindical e o estudantil" (GONÇALVES, 1990, p. 13).

Nesse cenário, destacavam-se as expectativas depositadas no papel que o processo educativo poderia ou deveria desempenhar com relação à problemática ambiental. Carvalho (1989, p. 102) afirma que a possibilidade da contribuição dos programas educativos, seja do ponto de vista da aquisição dos conhecimentos a respeito do meio, seja no tratamento de questões relacionadas com as alterações provocadas pela sociedade à natureza, tem sido considerada desde há muito tempo por diferentes grupos sociais.

Cabe destacar que, o que conhecemos, hoje, por Educação Ambiental, surgiu inicialmente com o movimento ecológico, por meio de uma prática que buscava chamar a atenção para a finitude e a má distribuição dos recursos naturais, e, em um segundo momento, foi se constituindo como "proposta educativa no sentido forte, isto é, que dialoga com o campo educacional, com suas tradições, teorias e saberes" (CARVALHO, 2006, p. 52). De acordo com Carvalho (2006), no Brasil, a Educação Ambiental apareceu na legislação desde 1973, como atribuição da primeira Secretaria Especial do Meio Ambiente (SEMA), "mas é principalmente nas décadas de 80 e 90, com o avanço da consciência ambiental, que a EA cresce e se torna mais conhecida" (CARVALHO, 2006, p. 52).

Como tentativa de compreensão da complexidade das questões ambientais, Bornheim (1985) afirma que, subjacente a essas questões, servindo-lhe de pano de fundo, existem as concepções que determinada sociedade têm de natureza e da relação sociedade-natureza. Nas palavras do autor, "a questão toda se concentra, portanto, no modo como a natureza se faz presente para o homem; ou melhor: no modo como o homem torna a natureza presente". (BORNHEIM, 1985, p. 18).

Segundo Gonçalves (1990, p. 23), "toda sociedade, toda cultura cria, inventa, institui uma determinada ideia do que seja a natureza". Assim, pode-se afirmar que o "conceito de natureza não é natural” (GONÇALVES, 1990, p. 23). Na verdade, é um conceito criado pelos homens, que constitui um alicerce por meio do qual cada sociedade edifica sua cultura.

No chamado mundo ocidental, a natureza tem sido pensada em oposição ao homem e à cultura. De um lado, existe o homem, de outro, a natureza. Essa visão dicotômica de natureza, embora existente desde o período clássico da antiguidade grega, sobretudo a partir da filosofia platônica, foi enfatizada a partir do século XVII. 
No entanto, houve época em que a forma de conceber a natureza era bastante diferente da que se firmou a partir do período clássico. No período pré-socrático, a concepção de natureza era muito abrangente e ia além do conceito que temos hoje. Natureza, para esses pensadores, era compreendida como physis. Segundo Bornheim (1993, p. 14):

[...] o conceito de physis é o mais amplo e radical possível, compreendendo em si tudo o que existe [...]. À physis pertencem o céu e a terra, a pedra, a planta, o animal e o homem, o acontecer humano como obra do homem e dos deuses e, sobretudo, pertencem à physis os próprios deuses.

Contudo, com as profundas transformações da sociedade, essa concepção de natureza e da relação sociedade-natureza foi substituída pela concepção dicotômica que hoje conhecemos, acentuada, como já apontado, a partir da modernidade, com a constituição da ciência moderna. O ideário ambiental de nossa civilização, de acordo com Carvalho (2006, p. 92) tem sido marcado pela "tensão entre o repúdio e o enaltecimento da natureza".

Assim, considerar a forma como a natureza é entendida por determinada sociedade é essencial para se repensar o modo como vivemos e como produzimos. E, de acordo com Bornheim (1985, p. 18), como já apontado, entender como determinada sociedade "torna a natureza presente" é fundamental para a superação dos impasses gerados pela problemática ambiental.

Tendo como referência essas ideias, realizou-se uma pesquisa para obtenção do título de mestre em Educação, defendida em 2009, cujos objetivos foram identificar, a partir da memória de velhas professoras, as concepções de natureza e da relação sociedade-natureza de velhas docentes que atuavam na rede pública estadual de uma cidade do interior do estado de São Paulo, nas décadas de 1960 e 1970.

A delimitação das décadas de 1960 e 1970 para a realização da pesquisa se justifica tendo em vista que, nesse período, os assuntos relativos ao que, hoje, designamos de temática ambiental ganhavam ênfase em decorrência do agravamento dos níveis de destruição da natureza em determinadas áreas do mundo. Além disso, considerando a Educação e, particularmente a escola como um espaço privilegiado para a discussão das questões ambientais, notase que, nessas décadas, a Educação Ambiental, surgida inicialmente no âmbito do movimento ecológico, não estava, ainda, incorporada ao universo escolar propriamente dito.

Pretende-se, por meio deste artigo, apresentar parte dos resultados encontrados, particularmente os referentes às concepções de natureza e da relação sociedade-natureza de velhas professoras.

\section{Metodologia}

Por meio da metodologia da história oral, foram realizadas nove entrevistas com professoras aposentadas que atuaram em estabelecimentos de ensino da rede pública primária estadual de uma cidade do interior do estado de São Paulo, nas décadas de 1960 e 1970, à época designados de grupos escolares; e que afirmaram ter trabalhado, em suas aulas, com questões relativas à temática ambiental, especificamente em relação à natureza e à relação sociedade-natureza. 
Mercadante, M.; Cavalari, R. M. F.

Inicialmente foram tomadas todas as providências no que diz respeito ao encaminhamento do projeto para apreciação do Comitê de Ética de Pesquisa envolvendo Seres Humanos da Universidade. Em seguida, houve um contato com cada uma das narradoras, para esclarecer como se daria o desenvolvimento da pesquisa. Para assegurar a privacidade das depoentes, optou-se, na apresentação deste trabalho, por trocar o nome de todas as professoras narradoras; optou-se, ainda, por trocar ou suprimir, sempre que necessário, os nomes das escolas, lugares e pessoas mencionados pelas professoras entrevistadas.

Para a composição do grupo de narradoras, foi utilizado o chamado "critério de rede" - no qual uma professora sugeriu a pertinência do depoimento de outra professora (GARNICA, 2004, p. 92). Registrou-se um total de trinta e seis contatos, dos quais foram selecionados nove para a realização das entrevistas.

As entrevistas foram realizadas a partir de um roteiro previamente elaborado, no entanto, suficientemente aberto de modo a permitir que as narrativas das experiências dessas professoras ocorressem da forma mais natural possível.

Para selecionar as professoras participantes da pesquisa, alguns critérios foram adotados, a saber: a afinidade das narradoras com a temática ambiental; a afirmativa - por parte das docentes - de terem abordado temas relacionados à natureza e a relação sociedade-natureza enquanto lecionavam, e o consentimento e disponibilidade para gravar os relatos.

Após a gravação dos relatos, seguiram-se os processos de transcrição literal e a textualização. Em seguida, o texto foi devolvido às professoras para a devida conferência e autorreconhecimento (MEIHY, 2005, p. 195).

Ao terminar o processo de transcrição, textualização e conferência por parte das narradoras, várias leituras foram realizadas e resultaram em descobertas que geraram um conjunto de dados que, posteriormente, foram organizados de maneira a responder as questões norteadoras da pesquisa.

\section{Memória, tempo e velhice}

Buscando enfrentar a tarefa de uma melhor compreensão dos temas referentes à memória, bem como a questão do tempo e o rememorar na velhice, apoiamo-nos em autores como Halbwachs, Duvignaud e Durkheim.

Ao se discutir o tema memória e ao se pensar nas regiões da experiência coletiva e individual, alguns aspectos chamam a atenção. Diante disso, entendemos que a questão da individualização, da coletividade, bem como da relação entre o tempo passado e o tempo presente que se consubstanciam na memória, são elementos importantes a serem destacados.

Halbwachs (2006, p. 29), em sua obra "A memória coletiva", argumenta que, em algumas circunstâncias, quando existe algum evento sobre o qual conservamos alguma informação, é frequente recorrermos a outras pessoas para fortalecermos e aperfeiçoarmos o que sabemos. Nesse sentido, nossas lembranças são também as lembranças de outras pessoas.

Segundo o autor, dos acontecimentos essenciais do passado de um grupo, denominados de "memória coletiva", retém-se apenas aquilo que ainda está vivo na consciência deste grupo: 
No primeiro plano da memória se destacam as lembranças dos eventos e das experiências que dizem respeito à memória de seus membros e que resultam de sua própria vida ou de suas relações com os grupos mais próximos, os que estiveram mais freqüentemente em contato com ele. (HALBWACHS, 2006, p. 51)

A ideia de que a memória coletiva é uma "corrente de pensamento contínuo", já que apreende do passado aquilo que é capaz de viver na consciência do grupo, nos remete à distinção feita por Halbwachs (2006, p. 102) entre "memória histórica" e "memória coletiva".

No prefácio da obra "A memória coletiva", de Halbwachs (2006), Duvignaud discute essa distinção e esclarece que, de um lado, situa-se a "memória histórica, pressupondo a reconstrução dos dados fornecidos pelo presente da vida social e projetada sobre o passado reinventado" (DUVIGNAUD, 2006, p. 13); do outro lado, situa-se a "memória coletiva, que magicamente recompõe o passado" (DUVIGNAUD, 2006, p. 13). Explica, ainda, que, para Halbwachs, a "memória coletiva" não se confunde com história, e que o termo "memória histórica" é contraditório, tendo em vista que a história diz respeito a uma "construção cristalizada por um grupo estabelecido para se defender da erosão permanente da mudança"; já a memória está relacionada à "mudança das perspectivas e seu relativismo recíproco" (DUVIGNAUD, 2006, p. 13-14).

Se a "memória coletiva" é uma "corrente de pensamento contínuo", pois é o passado que se perpetua e vive na consciência coletiva, pode-se dizer que, no conceito de memória coletiva, encontra-se a história vivida. Segundo Halbwachs (2006, p. 79), "nossa memória não se apoia na história aprendida, mas na história vivida".

Para Halbwachs (2006), a "memória coletiva" é importante no ato individual de rememorar. Segundo o autor, os "fatos e idéias que mais facilmente recordamos são do terreno comum" (HALBWACHS, 2006, p. 66). Por outro lado, se a força e estabilidade da "memória coletiva" estão atreladas a um conjunto de pessoas, não podemos nos esquecer que, enquanto integrantes de um grupo, são os indivíduos que agem, que experimentam e que lembram. Nesse sentido, "cada memória individual é um ponto de vista sobre a memória coletiva [...] este ponto de vista muda segundo o lugar que ali ocupo [...] esse mesmo lugar muda segundo as relações que mantenho com outros ambientes" (HALBWACHS, 2006, p. 69).

Segundo Duvignaud (2006, p. 13), a obra de Halbwachs situa "a aventura pessoal da memória, a sucessão dos acontecimentos individuais, que resulta de mudanças que ocorreram nas nossas relações com os grupos a que estamos misturados e nas relações que se estabelecem nesses grupos".

Assim, se é verdade que existe uma série de pensamentos que nos ligam a outras pessoas, que nos permitem apoiar na memória dos outros, também é verdade que existem as sensações que nos vêm das coisas, as quais só existem para nós (HALBWACHS, 2006).

Halbwachs (2006, p. 57) explica que "em cada consciência individual as imagens e os pensamentos que resultam dos diversos ambientes que atravessamos se sucedem segundo uma ordem nova e que, neste sentido, cada um de nós tem uma história”. Ainda segundo o autor, quando muitas correntes sociais se cruzam e se chocam em nossa consciência, surgem 
as "intuições sensíveis". Como essas "intuições sensíveis" não estão ligadas a nenhum ambiente, elas assumem as formas de estados individuais, os quais relacionamos a nós mesmos (HALBWACHS, 2006, p. 58).

Por estar sempre no presente, Halbwachs (2006, p. 60-61) argumenta que a "intuição sensível" não se recria por si mesma, pois "nossas percepções do mundo exterior se sucedem seguindo a mesma ordem de sucessão dos fatos e fenômenos naturais" (HALBWACHS, 2006, p. 60). Segundo o autor, cada vez que percebemos e que lemos os objetos, estamos inseridos em uma lógica social e nas relações que ela determina.

Os nossos sentimentos e gostos expressam contatos obtidos "com grupos diversos ou opostos e nossa parte em cada modo de ver é determinada pela intensidade desigual das influências que eles exerceram em separado sobre nós" (HALBWACHS, 2006, p. 65).

Em Durkheim (apud MANCUSO, 2007), encontram-se discutidas as dimensões das influências sociais, e é, ainda, a partir desse autor que, segundo Mancuso (2007, p. 5), surge a possibilidade de se "perceber a dimensão social nos fatos mais cotidianos e aparentemente banais e naturais". Ao realizar seu estudo, a autora afirma que

[...] veio de Durkheim a sugestão de trabalhar memórias individuais e, a partir delas, chegar a uma representação de cidade, ou de uma memória de cidade coletivamente construída que não fosse simplesmente a soma de memórias individuais em sua obra. (MANCUSO, 2007, p. 5)

De acordo com Mancuso (2007), esta proposta surgiu da ideia de pessoa discutida por Durkheim.

Para Durkheim (2000, p. 285): “A ideia de pessoa é produto de duas espécies de fatores. Um é essencialmente impessoal: princípio espiritual que serve de alma à coletividade. É ele, com efeito, que constitui a substância mesma das almas individuais".

O autor esclarece que este papel de individualização é desempenhado pelo corpo, pois, levando-se em conta que cada pessoa ocupa distintos pontos do espaço e do tempo, as representações coletivas apresentam-se a cada uma delas de formas diferenciadas: “ [...] como os corpos são distintos uns dos outros, como ocupam pontos diferentes do tempo e do espaço, cada um deles constitui um meio especial onde as representações coletivas vêm se retratar e se colorir diferentemente" (DURKHEIM, 2000, p. 285).

Para Durkheim (2000), a individualização diz respeito a um sujeito singular que se distingue de todos os outros e, além disso, "é um ser ao qual é atribuída autonomia relativa em relação ao meio com o qual está mais imediatamente em contato" (DURKHEIM, 2000, p. 286).

O autor alerta para o fato de que a vida social será mais rica se os indivíduos forem numerosos e distintos uns dos outros. Ao mesmo tempo, estes indivíduos distintos precisam estar "associados" para que haja vida social (DURKHEIM, 1999, p. 105).

Os indivíduos distintos que não veem de forma idêntica o mesmo mundo do qual fazem parte, recebem um conjunto de representações da sociedade. Estas representações isto é, o mundo de ideias e de sentimentos que constituem a unidade moral do grupo - são identificadas, por Durkheim (2000), à memória.

Em sua obra "Sociologia e filosofia", Durkheim (1961, p. 17) argumenta que "aquilo que nos dirige não são as poucas idéias que ocupam presentemente nossa atenção”. O autor 
explica que a memória - "resíduos deixados por nossa vida anterior, [...] os hábitos contraídos, os preconceitos, as tendências que nos movem sem que disso nos apercebamos [...] tudo aquilo que constitui nossa característica moral" (DURKHEIM, 1961, p. 17) - é capaz de governar a nossa vida. No entanto, a memória não se restringe à reprodução sem modificações do que recebemos anteriormente; fato que demonstra a sua contínua reconstrução. Assim, se a memória vincula-se ao passado, é no presente que rememoramos.

Esta relação entre o tempo passado e o tempo presente é outro aspecto importante que merece destaque ao se discutir a questão da memória, pois ela faz com que o passado se configure em um passado vivo, o qual está presente em nós e que, por sua vez, é lembrado no presente. Nesse sentido, Durkheim (1961) discute a atualização da memória: se a memória está associada a um tempo passado, não podemos nos esquecer de que o ato de rememorar ocorre no e pelos estímulos do tempo presente, pois "a vida representativa [...] não é formada de átomos separados uns dos outros; é um todo contínuo, no qual todas as partes se interpenetram" (DURKHEIM, 1961, p. 27).

Já Halbwachs (apud MANCUSO, 2000), em sua obra "Os quadros sociais da memória", nos remete ao conceito de quadros sociais da memória. Para o autor, esses quadros articulam o presente ao passado, pois dizem respeito aos estímulos presentes que levam à rememoração. O autor explica que:

não é o passado todo inteiro que exerce sobre nós uma pressão com vista a penetrar nossa consciência. Não é mais a série cronológica dos estados passados que reproduziria exatamente os acontecimentos antigos, mas são aqueles únicos entre eles que correspondem a nossas preocupações atuais que podem reaparecer. (HALBWACHS apud MANCUSO, 2000, p. 33)

Quando o passado é reconstruído no presente, temos um conjunto de representações e, portanto, trata-se de uma "reconstrução", e não "reprodução". A reconstrução do passado é feita a partir de uma perspectiva que se manifesta por meio dos lugares e das pessoas, ou seja, as lembranças emergem quando, por exemplo, se sente um cheiro ou se encontram pessoas que há tempo não se via. Mancuso (2000), ao tratar especificamente do rememorar do velho, tomando por base Halbwachs, afirma que: "a fala do velho é sempre uma fala sobre o tempo" (MANCUSO, 2000, p. 217). E interroga:

Os velhos, porém, poderiam ter outra referência que não o passado, quando, por causa da consumição dos tempos, o futuro é um sopro face à possibilidade da morte e o que se pode deixar para ele, o futuro, como herança, em um desejo de continuidade, é um passado vivido? (MANCUSO, 2000, p. 217-218)

Ainda com relação ao rememorar de velhos, Tenca (2006) defende que ouvir e gravar o depoimento de velhos faz parte de um processo mais amplo voltado para a revalorização do papel do velho na sociedade. O autor defende que não se trata de "dar voz" ao velho e nem de falar por eles. Não se trata de "dar existência a algo que estivesse ausente do mundo dos 
Mercadante, M.; Cavalari, R. M. F.

homens" (TENCA, 2006, p. 44). Para este autor, o trabalho do pesquisador consiste em "registrar os feitos de indivíduos construindo o mundo dos homens e das coisas" (TENCA, 2006, p. 44).

Por todos esses argumentos, considera-se importante salientar que, para a identificação das concepções de natureza e da relação sociedade-natureza, por meio da memória de velhas professoras, considerou-se o fato de que essas narradoras não são seres isolados e/ou desintegrados da sociedade; ao contrário: possuem intensa vida social. Suas lembranças são carregadas de significados e se manifestam no tempo presente. Suas lembranças são, também, as lembranças de outras pessoas. Contudo, são indivíduos, que, apesar de pertencerem a um grupo com características semelhantes, relembram com particularidades o tempo em que lecionavam.

\section{Contando lembranças: a natureza e a relação sociedade-natureza na memória de velhas professoras}

Por meio da leitura atenta dos relatos, foi possível observar que as docentes tornam a natureza presente por meio de diferentes concepções. A natureza como "tudo o que existe", como "vida", uma concepção "religiosa" de natureza, a natureza como a "grande provedora de recursos naturais", a natureza como "universo", como "mãe de todas as coisas", e a natureza como aquela que "tudo recicla" são as concepções de natureza presentes nos depoimentos coletados. Várias professoras consideraram, ainda, a natureza como aquela que "pode dar respostas e reagir" às ações desmedidas do homem. Além disso, a natureza apareceu como aquela que "deve ser preservada", pois disso depende a manutenção da nossa própria vida.

Vale esclarecer que algumas concepções, embora com características semelhantes, apresentam pequenas variações, como no caso dos depoimentos das professoras Joana, Márcia, Rita e Zulmira, as quais consideram que "a natureza é tudo o que existe". Esta concepção de natureza se aproxima daquilo que Carvalho (1989) denominou de concepção genérica, ao observar as respostas de um determinado grupo de professores do então $1^{\circ}$ grau com relação ao entendimento que eles tinham a respeito do termo "ambiental". Segundo o autor, nesta concepção, "os professores entendem o ambiental de forma muito genérica, traduzindo-o como o 'meio onde se vive', 'aquilo que nos cerca', etc." (CARVALHO, 1989, p. 143).

Para a professora Joana, "a natureza é tudo o que envolve o ser humano", incluindo o próprio ser humano. É também “tudo o que a gente vê", como, por exemplo, a criação, a planta, o céu e as pedras:

"A natureza é tudo o que envolve o ser humano. Eu acredito nisso! [...]. O ser humano está influenciado com a natureza em tudo... o ser vivo! Nós somos seres vivos e estamos envolvidos, influenciados inteirinhos no meio ambiente [...]. A natureza é tudo! Até você é uma natureza! Eu também! Eu acredito nisso! Eu acho que a natureza é tudo para nós! A criação, a planta, esse céu maravilhoso que nós temos, os rios, as pedras, tudo! [...] Porque tudo o que a gente vê é a natureza". (professora Joana) 
A professora Márcia também considera o ser humano como sendo parte integrante da natureza. Considera, ainda, a natureza como sendo "tudo o que nos rodeia": os animais, as plantas, o sol, as estrelas e o ar:

"Eu sempre gostei da natureza e, para mim, tudo o que nos rodeia faz parte da natureza. Tudo, tudo! Os animais, as plantas, o sol, as estrelas, o ar (ou luar), tudo é natureza. Tudo! O próprio ser humano também é a natureza. Tudo! O ambiente em que nós vivemos é a natureza". (professora Márcia)

Para a professora Rita, a natureza diz respeito ao lugar no qual vivemos; está relacionada àquilo que está próximo e àquilo que está distante de nós, como o céu, as estrelas e a lua. Segundo a professora: é tudo "aquilo que está junto da gente", que é "imediato", mas é também "aquilo que a gente nem về". Considera, ainda, a natureza como aquela que faz parte de um sistema que tem o seu próprio ciclo e a capacidade de "rapidamente se refazer", apesar das investidas recebidas por parte do ser humano:

"A natureza para mim é tudo. É tudo, é tudo! Eu acho que natureza começa do nosso local, de onde eu estou [...]. Depois a gente vai expandindo. Você vai imaginando as suas viagens, os lugares que vai, tudo que pode ser visto, as montanhas, o mar... você vai de um extremo ao outro. Depois você começa a ampliar um pouco mais o horizonte e começa a ver o céu, as estrelas, a Lua. Daí você já vai para o computador pesquisar os astros e não termina nunca mais. Você entendeu? Então, a natureza é desde o imediato, aquilo que está junto da gente até aquilo que a gente nem vê, mas que dá para estudar e olhar [...]. Então, quer dizer que, a natureza, se nós deixarmos, ela sozinha se cuida, ela se refaz muito rapidamente, graças a Deus, que é o que evita que a gente esteja em um mundo devastado [...]. Mesmo um animalzinho, que aparece aqui de vez em quando e que é prejudicial, como a cobra que vem para comer o ovo de passarinho, mesmo essa eu deixo que viva, porque é um sistema do meio ecológico. Várias vezes eu peguei aquele passarinho de rabo cumprido bicando o rabo do lagarto, porque o lagarto vai comer o seu ovo! É a natureza se acomodando! Cada um defendendo o seu espaço”. (professora Rita)

A professora Zulmira também afirma que a natureza é tudo, ou, ainda, que a natureza é vida. Apresenta a natureza como sendo essencial à sobrevivência humana, pois sem ela "não existe vida", e o homem é compreendido como aquele que é dependente dos recursos que ela tem a oferecer:

"Natureza para mim é tudo! Para mim não existe vida sem natureza! Não existe vida sem a natureza, sem a água, sem a planta... Por que é que o mundo está ficando poluído como está agora? Porque está aca- 
Mercadante, M.; Cavalari, R. M. F.

bando o verde que purifica o ar! Sumiu, acabou! O ser humano está morrendo porque a natureza está acabando". (professora Zulmira)

Ainda dentro de uma perspectiva "genérica" pode-se citar, como exemplo, o depoimento da professora Fátima. Segundo essa professora, a natureza é "vida" e, assim sendo, a sobrevivência humana está intimamente relacionada com a sobrevivência da natureza: "Natureza para mim é vida! Sem ela nós estamos perdidos! E a natureza é a nossa vida. Nós não vivemos sem ela! É assim que eu entendo!” (professora Fátima).

Note-se que, além de considerar a natureza "como tudo", no depoimento da professora Maria Inês aparece uma concepção religiosa, espiritual de natureza. Nesta concepção a natureza é uma "dádiva, uma criação divina" (ARGENTON; CAVALARI, 2001, p. 7). De acordo com a professora, a natureza, essa criação divina, está relacionada, também, à maneira de tratar o outro (a pessoa, a família):

"A natureza para mim é essa coisa linda que Deus fez. Toda essa coisa linda que Deus fez. Tem a natureza e tem a outra parte espiritual da natureza, a vida, a família. A família é tudo [...]. Como eu disse para você, eu acho que a natureza é tudo. Eu acho que a natureza é a coisa mais linda. É a forma de você tratar a pessoa, a compreensão que você tem, o modo de tratar a família". (professora Maria Inês)

A concepção religiosa de natureza pode ser identificada, também, no depoimento da professora Elvira, quando esta afirma que vê Deus na natureza, nas plantas e nas flores, e que acredita que tudo isso é regido por um "ser sobrenatural":

"Eu vejo Deus na natureza. Eu já falei para você que eu sou meio espiritualizada e religiosa. Eu vejo Deus nas plantas e nas flores. O pôr do Sol é uma coisa sobrenatural. Seja Ele o Confúcio, o Buda...! Eu acredito que tem um ser sobrenatural regendo tudo isso". (professora Elvira)

O depoimento da professora Teodora também mostra uma concepção religiosa de natureza. Neste, além de a natureza ser apresentada como "primordial", por isso devendo ser preservada, é, apresentada, ainda, como aquela na qual existe a "mão de Deus":

"Eu acho que a natureza é primordial. Eu vejo a mão de Deus na natureza. Se você pega, por exemplo, uma lagarta que é listrada de preto e laranja na horizontal e, depois, quando ela forma a pulpa, ela fica laranja e preta na horizontal, como pode acontecer isso? Não é Deus que faz essas coisas?". (professora Teodora)

No depoimento da professora Marta, foi possível identificar, ainda, as seguintes concepções de natureza: a natureza como sendo "a grande provedora de recursos naturais", já que é dela que tiramos tudo o que precisamos para a nossa sobrevivência; a natureza como "universo" e como 
"mãe de todas as coisas", pois sem ela nada existe; a natureza como sendo aquela que "tudo recicla", tendo em vista que, por meio da decomposição, os nutrientes que fazem parte dessa natureza, e que estão, portanto, inseridos dentro de um ecossistema, são continuamente reciclados:

"É pela natureza que a gente tira tudo! [...]. De onde vêm os alimentos? Da natureza, não é? De onde vem material de construção? Da natureza! De onde vem o minério? Da natureza! Tudo! De onde vem a água? Da natureza! Tudo! [...]. Eu trabalhei com primeiras séries e sempre falei de natureza com os alunos. A natureza, a gente sabe o que é, mas é difícil encontrar uma definição. A natureza, ah, quando se fala em natureza eu penso até no universo. A natureza é a mãe de todas as coisas. Porque sem a natureza não tem nada. Eu sempre falava para os meus alunos: "Olha, você está comendo uma fruta, enfim, comendo alguma coisa. Você sabe que quando morre um animal, esse animal é decomposto. Ele é transformado em nitratos, fosfatos e etc... $\mathrm{E}$ as plantas absorvem esses elementos como nutrientes. Você deve estar comendo algumas moléculas que foi algum...". É verdade! Eu falei: "Será que eu tenho algum átomo pelo menos que foi do Leonardo Da Vinci?”. Bem que eu gostaria! Porque a natureza recicla, recicla tudo! Os alunos não gostam de estudar ciclo do oxigênio, ciclo da água, ciclo do carbono, ciclo do nitrogênio. Esses são os elementos que mais aparecem na natureza. Tudo que é ser vivo tem água, tem hidrogênio, tem carbono e tem oxigênio. Por isso se estudam os ciclos da natureza. É tudo reciclado [...]”. (professora Marta)

É importante ressaltar que, embora essas concepções à primeira vista possuam características diferentes, em alguns casos, estão intimamente relacionadas e muito próximas umas das outras. É o caso, por exemplo, da concepção religiosa de natureza. Nesta concepção, como vimos, algumas docentes relacionaram a natureza a Deus, outras, à "criação divina", e, outras, ainda, a um "ser sobrenatural".

A análise dos depoimentos evidenciou, ainda, certa preocupação, por parte das docentes, em relação aos cuidados e à preservação da natureza. No caso da professora Rita, a preocupação com a natureza parece estar relacionada com a questão da própria sobrevivência: "Sobre a natureza a gente falava tudo, sempre a gente deu bastante ênfase sobre a natureza, sobre a preservação, por causa da nossa própria vida" (professora Rita).

Enquanto alguns relatos das professoras parecem apresentar indícios de certa preocupação com relação à preservação da natureza, outros depoimentos parecem dar uma ênfase à natureza como a grande provedora de recursos naturais para a subsistência humana. Nota-se a natureza como a grande provedora de recursos naturais no relato da professora Fátima:

"Eu falava da importância e das riquezas que nós temos nas nossas matas, nos nossos campos. Quantos remédios nós temos! É uma coisa incrível! Infelizmente, nem a maioria dos médicos pode aproveitar disso. Tudo nós compramos de fora [...]”. (professora Fátima) 
No que se refere à relação sociedade-natureza, um aspecto observado nos depoimentos analisados diz respeito à relação conflituosa que se estabeleceu entre o homem e a natureza. Pode-se afirmar que, no geral, o homem foi apresentado como sendo o grande vilão, como aquele que destrói a natureza, sendo caracterizado pelas docentes, entre outros adjetivos, como: "ruim", "malvado", "ganancioso" e "ignorante".

No depoimento da professora Rita, observa-se que o homem é apresentado como sendo aquele que nunca está satisfeito; e, com sua "sede de poder", deixa-se dominar pela "ganância" e pela "ambição". Reconhece a necessidade de intervenção do ser humano no sentido de usufruir do que a natureza tem a oferecer, já que "a floresta tem muita coisa para ser explorada", mas chama a atenção para o fato de que precisamos "saber conviver com aquilo que temos a fim de preservar nossa própria sobrevivência".

Deve ser ressaltado, ainda, que uma das professoras, a professora Elvira, parece incluir a relação homem-homem no processo de relação homem-natureza; no entanto, essa ideia, anunciada no início do depoimento, não é desenvolvida ao longo do mesmo. Percebe-se, ainda, por meio da análise da entrevista dessa professora, certa "dependência" da natureza com relação ao ser humano: "o meio ambiente não existiria se não tivesse o homem para habitá-lo". Para a docente, a natureza é "valoriz̨ada" devido à existência do ser humano: "se o homem não existisse, o meio ambiente não teria valor". No entanto, alerta para o fato de que a manutenção da nossa vida está atrelada à conservação dos recursos oferecidos pela natureza: "ou você conserva ou você não vai ter recursos da natureza para manter a vida mais tarde?'.

Nota-se, ainda, que a docente reconhece que a relação do homem com a natureza foi se modificando com o passar do tempo, de acordo com a cultura de cada sociedade. Sem considerar que, hoje, há uma maior explicitação da problemática ambiental, ela argumenta que, antigamente, era uma "coisa mais natural e pacifica" e "boje é uma coisa mais imposta", pois, se não preservarmos os recursos naturais, não haverá vida mais tarde:

"Hoje também piorou muito a forma como os homens se tratam. Está feio agora. Antigamente era uma coisa mais calma. A gente vê muitas coisas horríveis na televisão. Antigamente acontecia muita coisa ruim também, mas era escondido. A gente não sabia. Você vê esse caso da menina Isabela! É um caso que talvez, em outras épocas, tivesse acontecido coisa parecida. Hoje, com os meios de comunicação fica tudo aberto para o povo. Mas esse não é o nosso assunto [...]. Só queria dizer que o meio ambiente não existiria se não tivesse o homem para habitá-lo. Se o homem não existisse, o meio ambiente não teria valor. Mas essa relação, desde a criação do mundo até hoje, foi se modificando de acordo com a cultura, de acordo com a sociedade. $\mathrm{Na}$ minha época existia uma harmonia maior entre o homem e a natureza. Então, eu acho que antigamente era uma coisa mais natural e pacífica. Hoje é uma coisa mais imposta: ou você conserva ou você não vai ter recursos da natureza para manter a vida mais tarde!". (professora Elvira)

Já a professora Teodora afirma que são poucas as pessoas que se preocupam com a natureza. O ser humano aparece no depoimento da docente como sendo "mal educado" e "igno- 
rante". No entanto, mesmo sem dispensar essas explicações mais individuais (homem "mal educado" e "ignorante") para as causas da degradação ambiental, em certo momento, a professora Teodora discute muito rapidamente a questão dos dirigentes políticos do nosso país em uma tentativa de buscar uma explicação mais ampla, mais política, para as causas da degradação ambiental. Chama a atenção, ainda, a distinção feita pela professora, já no início do excerto destacado, entre informação e educação. Para a docente, a informação por si só não basta para provocar reflexões e/ou mudanças de atitudes com relação à degradação ambiental. Alerta para o fato de que, mesmo com todas as informações divulgadas pela mídia, as pessoas continuam interferindo negativamente no meio ambiente.

Essa distinção expressa pela professora Teodora em seu depoimento encontra sustentação em Severino (2001), que defende que a Educação é um processo de humanização e afirma que este processo não é automático e nem "decorrência mecânica da vida da espécie" (SEVERINO, 2001, p. 12). A escola tem, assim, um importante papel no processo de transformação da sociedade, já que, nesta perspectiva humanizadora, ela não é vista como simples reprodutora dos sistemas hegemônicos de poder. Sem idealizar a escola neste processo de transformação social e a Educação Ambiental na busca de solução para os problemas socioambientais, acredita-se que elas são, antes de tudo, um caminho para o desenvolvimento de um pensamento crítico sobre a realidade socioambiental na qual estamos inseridos.

É interessante observar, ainda, que, ao mesmo tempo em que a professora Teodora afirma que o povo é bem informado, afirma, também, que a situação de degradação ambiental acontece "por causa da ignorância". Cabe, aqui, questionar sobre o sentido que a professora está dando para os termos informação e ignorância. Será que, para a professora, o termo ignorante está relacionado com a falta de conhecimento sistematizado?

"Eu acho que o povo é muito mal educado. Mal informado não! Por-
que você vê na televisão chamando a atenção por causa do meio ambi-
ente, sobre as enchentes, sobre as garrafas no rio... As pessoas destro-
em a natureza para construir prédios! Isso acontece por causa da igno-
rância. É engraçado porque as pessoas falam assim: 'Escolha bem em
quem você vai votar'. Então você escolhe. Só que chega lá na ilha da
fantasia - porque Brasília é a ilha da fantasia - eles mudam. Não adianta
você escolher. Votei muito, agora eu não preciso mais [...]. Fala-se tan-
to do problema da água, do efeito estufa... Este assunto me preocupa
muito. Não por minha causa, porque eu não vou estar aqui, mas por
causa dos meus filhos, netos e bisnetos! Conforme previsões faltarão
água e alimentos. Eu me preocupo muito com o futuro!”. (professora
Teodora)

Outra entrevistada identificou o homem como sendo aquele que destrói a natureza e afirmou a existência de duas correntes de pensamento diferenciadas entre os cientistas em relação ao efeito estufa e ao aquecimento global: aqueles que acreditam que a causa da destruição da natureza está exclusivamente relacionada ao homem, e aqueles que reconhecem não ser apenas o homem que interfere na natureza, já que esta possui seu próprio ciclo. Comentou, também, a questão do aumento populacional. Esta professora parece ter presente a questão de 
Mercadante, M.; Cavalari, R. M. F.

a interferência humana na natureza não ser tão intensa e nem o principal motivo dos problemas ambientais, uma vez que ela afirma que a própria Ciência não tem uma posição clara a respeito desse tema.

Em que pesem as considerações a respeito da natureza e da relação sociedade-natureza a partir dos relatos das professoras, importa dizer que, no decorrer das entrevistas, em vários momentos, as professoras compararam o ensino de "antigamente" com o ensino que temos hoje. A professora Márcia, ao fazer a comparação entre o ensino atual e o do passado, afirma que a "preocupação com a natureza" e "a consciência de que os recursos não são inesgotáveis" são maiores atualmente do que no tempo que lecionava.

Pode-se observar, pelo relato dessa professora, que, além de reconhecer a importância de se trabalharem os temas relacionados à natureza com os alunos, a docente mostrou-se consciente de que o contexto vivenciado naquele período era outro, "eram outros tempos", e que, se tivesse naquele tempo a consciência que tem hoje em relação às questões ambientais, teria feito "muito mais do que fez naquela época".

De fato, não podemos desconsiderar as especificidades sociopolítico-econômicas vivenciadas naquele contexto pelas docentes. Apesar de ser uma época em que o movimento ambientalista estava se constituindo e os problemas relativos à degradação ambiental passavam a ser denunciados com mais ênfase, é importante dizer que, nas décadas de 1960 e 1970, o que nós conhecemos, hoje, como Educação Ambiental, não estava, ainda, incorporado ao universo escolar, motivo pelo qual as próprias docentes reconhecem que se falava muito de natureza com os alunos, no entanto, esses conteúdos eram tratados com uma abordagem diferente daquela que seria trabalhada hoje.

\section{Considerações finais}

$\mathrm{Na}$ tentativa de identificar as concepções de natureza e de relação sociedade-natureza baseando-se nas vozes de velhas professoras, pode-se afirmar que os resultados encontrados estão atrelados a uma história múltipla, na qual as experiências individuais evocadas do passado transformaram-se em experiências coletivas inseridas no presente, tal como defende Halbwachs (2006). Assim sendo, essas experiências estão repletas de diferentes pontos de vista e opiniões diversas acerca de um mesmo tema.

A partir do referencial teórico adotado, cumpre destacar que, ao tentarmos identificar as concepções de natureza e de relação sociedade-natureza por meio da memória de velhas professoras, entendemos que esta se constitui por meio de estímulos do tempo presente, processo designado por Halbwachs (apud MANCUSO 2000, p. 36) de "quadros sociais da memória". A partir desta perspectiva, "não é o passado que explica o presente, é o presente que explica o passado" (HALBWACHS apud MANCUSO 2000, p. 36).

Assim sendo, as concepções que as professoras têm hoje de natureza e de relação sociedade-natureza é a memória coletiva, mas é, também, o "quadro social da memória" (HALBWACHS apud MANCUSO 2000, p. 36). Nesse sentido, são as concepções que elas têm hoje de natureza e da relação sociedade-natureza, historicamente construídas, que fazem com que elas selecionem determinados aspectos do passado. 
Memórias de velhas professoras: ...

Embora não seja objetivo do presente artigo estabelecer uma análise comparativa entre as concepções de natureza e da relação sociedade-natureza presentes nas décadas de 1960 e 1970, na memória de velhas professoras, pelos dados encontrados podemos inferir que muitas daquelas concepções ainda estão presentes na escola hoje. Além disso, acreditamos que tentar compreender como a natureza e a relação sociedade-natureza se fazem presentes na memória dessas velhas professoras, pode contribuir para a construção de novas formas de relação sociedade-natureza nos dias atuais.

\section{Referências}

ARGENTON, E. C; CAVALARI, R. M. F. Concepções de natureza entre os professores de ciências do $3^{\circ}$ e $4^{\circ}$ ciclos do Ensino Fundamental. In: ENCONTRO DE PESQUISA EM EDUCAÇÃO AMBIENTAL, 1., Rio Claro, 2001. Anais... Rio Claro: Unesp, 2001. 1CD ROM.

BORNHEIM, G.A. Filosofia e política ecológica. Revista Filosófica Brasileira, Rio de Janeiro, v. 2, n. 1, p. 16-24, 1985.

Os filósofos pré-socráticos. 9. ed. São Paulo: Cultrix, 1993.

CARVALHO, I. C. de M. Educação ambiental: a formação do sujeito ecológico. 2. ed. São Paulo: Cortez, 2006.

CARVALHO, L. M. A temática ambiental e a escola de $1^{\circ}$ grau. 1989. 282 f. Tese (Doutorado em Educação) - Faculdade de Educação, Universidade de São Paulo, São Paulo, 1989.

DURKHEIM, E. Sociologia e filosofia. Rio de Janeiro: Forense, 1961.

As regras do método sociológico. 2. ed. São Paulo: Martins Fontes, 1999. (Coleção Tópicos).

As formas elementares da vida religiosa: o sistema totêmico na Austrália. 2. ed. São Paulo: Martins Fontes, 2000.

DUVIGNAUD, J. Prefácio. In: HALBWACHS, M. A memória coletiva. São Paulo: Centauro, 2006. p. 7-16.

GARNICA, A. V. M. História oral e educação matemática. In: BORBA, M. C. (Org.). Pesquisa qualitativa em educação matemática. Belo Horizonte: Autêntica, 2004. p. 77-98.

GONÇALVES, C. W. P. Os (des)caminhos do meio ambiente. São Paulo: Contexto, 1990.

HALBWACHS, M. A memória coletiva. São Paulo: Centuro, 2006. 
Mercadante, M.; Cavalari, R. M. F.

MANCUSO, M. I. R. A cidade na memória de velhos moradores. In: CONGRESSO BRASILEIRO DE SOCIOLOGIA, 13., Recife, 2007. Resumos... Recife, 2007. v. 1, p. 281-281.

A cidade na memória de seus velhos: estudo sobre São Carlos, Itirapina e arredores. 2000. 224 f. Tese (Doutorado em Sociologia) - Universidade de São Paulo, São Paulo, 2000.

MEIHY, J. C. S. B. Manual de história oral. 5. ed. São Paulo: Loyola, 2005.

SEVERINO, A. J. A relevância social e a consistência epistêmica da pesquisa em educação: alguns subsídios para se avaliar a pesquisa em educação ambiental. Educação: teoria e prática, Rio Claro, v. 9, n. 16/17, p. 10-16, 2001.

TENCA, A. Senhores dos trilhos: racionalização, trabalho e tempo livre nas narrativas de ex-alunos do curso de ferroviários da antiga paulista. São Paulo: Editora da UNESP, 2006.

Artigo recebido em 23/12/2011. Aceito em 06/04/2012. 